CUAD. CONTAB. / BOGOTÁ, COLOMBIA, 17 (44): 349-375 / JULIO-DICIEMBRE 2016 / 349

\title{
Sistemas de gestión de costos en las cooperativas de ahorro y crédito de Barranquilla*
}

doi:10.11144/Javeriana.cc17-44.sgcc

\section{Jorge Enrique Otálora-Beltrán}

Contador público. Magíster en administración e innovación, Universidad Simón Bolívar. Especialista en tributación, Universidad del Norte. Especialista en estudios pedagógicos, Universidad de la Costa, CUC. Docente investigador de tiempo completo, CUC.

Correo electrónico: Jotalora@cuc.edu.co

\section{Jorge Carlos Borda-Viloria}

Administrador de empresa. Magíster en administración e innovación, Universidad Simón Bolívar. Especialista en estudios pedagógicos y finanzas y sistemas, Universidad de la Costa, CUC. Docente investigador de tiempo completo, CUC.

Correo electrónico: Jborda1@cuc.edu.co

\author{
Adalberto Enrique Escobar-Castillo \\ Contador público, Universidad de la Costa, CUC. \\ Maestrante en Administración, Universidad de la Costa, \\ CUC. Investigador miembro del grupo GICADE de la \\ misma institución. Joven investigador COLCIENCIAS, \\ convocatoria 673 de 2014.
}

Correo electrónico: Aescobar2@cuc.edu.co 
Resumen El objetivo del presente artículo es la identificación de los sistemas de gestión de costos tradicionales utilizados en las cooperativas de ahorro y crédito de Barranquilla y sus diferentes problemas al momento de cimentar el proceso de toma de decisiones financieras por parte de los agentes encargados de hacerlo, que recurren a la metodología $\mathrm{ABC}$ como una opción eficiente para fundamentar este proceso en este tipo de organizaciones. Con esta finalidad, se estableció una investigación cuantitativa de alcance descriptivo, utilizando como instrumento de recolección de información primaria una encuesta tipo Likert, aplicada a las instituciones antes mencionadas, las cuales fueron seleccionadas mediante el muestreo probabilístico aleatorio simple. Los resultados demuestran que las cooperativas que ejecutan actividades financieras en Barranquilla suelen utilizar sistemas de costos tradicionales de bases históricas y estimadas que presentan un alto grado de dificultad al momento de cimentar la toma de decisiones, motivo por el cual los funcionarios encargados de procesar y revelar la información contable consideran que las técnicas y métodos característicos del sistema de costos $\mathrm{ABC}$ facilitan una adecuada asignación de los costos indirectos de fabricación, CIF, y consecuentemente propician un proceso de toma de decisiones con un alto grado de eficiencia.

Palabras clave Sistema de costo; $A B C$; gestión; toma de decisiones

\section{Código JEL L31, M41}

\section{Cost Management Systems in the Savings and Credit Cooperatives of Barranquilla}

\footnotetext{
Abstract The purpose of this article is to identify the traditional cost management systems used in the credit cooperatives of Barranquilla and the different problems they face when laying the foundations of the financial decision-making process by the agents in charge of said process. They make use of the $\mathrm{ABC}$ methodology as an efficient option to base this process for this type of organizations. To this end, we es-
}

tablished a quantitative research of descriptive scope using a Likert-type survey as the tool for the collection of primary information, applied to the aforementioned institutions, which were selected through simple random probability sampling. Results show that cooperatives that carry out financial activities in Barranquilla often use traditional cost systems with historical and estimate foundations that show a high degree of difficulty of laying the foundations of the decision-making process at the moment. This is why the employees responsible for processing and disclosing the accounting information consider that the techniques and methods of the $\mathrm{ABC}$ cost system facilitate an adequate allocation of indirect manufacturing costs, CIF, and, consequently, favors a decisionmaking process with a high degree of efficiency.

Keywords Cost system; ABC; management; decision making

\section{Sistemas de gestão de custos nas cooperativas de poupança e crédito de Barranquilla}

Resumo O objetivo do atual artigo é a identificação dos sistemas de gestão de custos tradicionais utilizados nas cooperativas de poupança e crédito de Barranquilla e os diferentes problemas na hora do processo de tomada de decisões financeiras por parte dos agentes encarregados, que recorrem à metodologia $\mathrm{ABC}$ como opção eficiente para alicerçar tal processo neste tipo de organizações. Para esse fim, estabeleceu-se pesquisa quantitativa de escopo descritivo, utilizando como instrumento de coleta de informações primárias um inquérito tipo Likert aplicado às instituições acima mencionadas, as quais foram selecionadas mediante amostragem probabilística aleatória simples. Os resultados mostram que as cooperativas que desenvolvem atividades financeiras em Barranquilla acostumam utilizar sistemas de custos tradicionais de bases históricas e estimadas apresentando alto grau de dificuldade na hora da tomada de decisões, motivo pelo qual os funcionários encarregados de processar e divulgar as informações contábeis acham que as técnicas e métodos característicos do sistema de 
custos $\mathrm{ABC}$ facilitam uma adequada alocação dos custos indiretos de fabricação, CIF, e consequentemente propiciam um processo de tomada de decisões com alto grau de eficiência.

Palavras-chave Sistema de custo; ABC; gestão; tomada de decisões

\section{Introducción}

La contabilidad se ha establecido como una ciencia dotada de técnicas y procedimientos tendientes a la identificación, medición, valoración y revelación de las diferentes transacciones con incidencia económica y social en la estructura financiera de una organización, que les permite a estas organizaciones financieras cimentar el proceso de toma de decisiones con base en informes cuantitativos y cualitativos que muestran la situación financiera de la empresa en un período determinado y los cambios que pueda experimentar este escenario, los resultados de las operaciones efectuadas en un determinado período operacional y los efectos que estos generan sobre la estructura patrimonial.

Tomando como referencia lo diverso y complejo de las necesidades de las organizaciones como producto de las obligaciones que exhiben estas con los accionistas y asociados, el capital intelectual inmerso en ellas, el Estado, los clientes y proveedores, y la sociedad en general, la contabilidad - como ciencia de naturaleza social que busca dar cuenta del estado actual de las relaciones de un segmento de la realidadadopta una serie de subdivisiones de acuerdo a las funciones y objetivos que cumpla en la empresa; de esta manera, en el contexto empresarial, se pueden hallar la contabilidad financiera, fiscal, de gestión y, en especial, la contabilidad de costos, relacionada con la identificación, medición, valoración y control de las erogaciones necesarias y obligatorias en el proceso de producción o en la prestación de servicios, mediante la implementación de sistemas de gestión orientados al suministro constante de información relevante, útil y oportuna.

Por este motivo, la finalidad esencial del presente artículo es la identificación de los sistemas de gestión de costos tradicionales utilizados en las cooperativas de ahorro y crédito de Barranquilla y los diferentes problemas que enfrentan los agentes encargados de hacerlo al momento de cimentar el proceso de toma de decisiones financieras. En este tipo de organizaciones, la metodología $\mathrm{ABC}$ es una opción eficiente para fundamentar este proceso; el artículo también analiza la importancia del sistema de costos $\mathrm{ABC}$ como herramienta financiera para la toma de decisiones en las cooperativas de ahorro y crédito de Barranquilla.

Como instituciones económicas y sociales, las cooperativas deben fundamentar sus operaciones por medio de instrumentos de naturaleza estratégica que les permitan hacerles frente a los múltiples retos originados en primera instancia por las constantes necesidades de los agentes de mayor vulnerabilidad de la sociedad que ellas deben suplir y de las exigencias provenientes de un mercado cada vez más especializado que exige de las organizaciones un alto nivel de eficiencia y efectividad en los procesos y políticas corporativas.

Las instituciones solidarias inmersas en el cooperativismo y que ejercen su objeto social en el subsector del ahorro y crédito en la ciudad de Barranquilla, manifiestan que la metodología 
utilizada para asignar las erogaciones necesarias y obligatorias para llevar a cabo su objeto social, no les permite instituir un adecuado proceso de toma de decisiones, en razón a que la gran mayoría de ellas adjudica estos sacrificios directamente a los gastos operacionales o en su defecto propenden por la utilización de sistemas de costos que se categorizan como tradicionales con bases históricas y predeterminadas, que poseen grandes problemas al momento de fundamentar el proceso decisorio.

\section{Fundamentación teórica}

Jorge Caldera, Pilar Baujín-Pérez, Vicente Ripoll-Feliu y Vladimir Vega-Falcón (2007) manifiestan que el auge de la contabilidad de costos como herramienta de gestión es consecuencia de las dinámicas impuestas por la revolución industrial, fenómeno económico, cultural y social caracterizado por la masificación de las operaciones efectuadas por las organizaciones a raíz de la utilización de las máquinas a vapor y por la internacionalización de las relaciones mercantiles. Estas situaciones pusieron al descubierto la necesidad de las empresas de utilizar procedimientos y procesos institucionales que propendieran por la identificación, medición, valoración y control de las erogaciones obligatorias e indispensables para el desarrollo de las actividades efectuadas por ellas.

Por otra parte, Jeffrey G. Miller y Thomas E. Vollmann (1985) expresan que, a raíz de la complejidad que adquirieron los procedimientos administrativos en las organizaciones, se desarrolló la necesidad de aumentar los contro- les sobre los $\mathrm{CIF}^{1}$ (costos indirectos de fabricación), por el peso de esta clase de erogaciones en los costos de manufactura ${ }^{2}$.

En este sentido, la contabilidad de gestión surge como una herramienta institucional que por medio de instrumentos cuantitativos y cualitativos propende por la captación, registro, evaluación, análisis y transmisión de información financiera y no financiera, con la finalidad esencial de cimentar el proceso de toma de decisiones, con respecto a la consecución de los objetivos corporativos y la creación de estrategias que ayuden a la organización a ser sostenible y competitiva en el mercado, mediante la generación de valor agregado en todos los procesos que la integran (Caldera, Baujín-Pérez, Ripoll-Feliu \& Vega-Falcón, 2007).

\subsection{Contabilidad de gestión como herramienta para la toma de decisiones}

En lo concerniente a lo que representa la contabilidad de gestión en el contexto que circunscribe las operaciones efectuadas por las organizaciones empresariales, diversos autores han esbozado sus aserciones de acuerdo a su enfoque particular; sin embargo, todos coinciden en que esta se establece como un medio por el cual los órganos administrativos cimentan el proceso de dirección de las empresas.

Inicialmente, Carlos Fernando Cuevas-Villegas (2001) enfatiza que, a raíz de las exigencias

\footnotetext{
1 Francisco Jiménez-Boulanger y Carlos Luis Espinoza-Gutiérrez (2007) definen los CIF como todos aquellos costos que no son fácilmente identificables con el bien o servicio prestado a la sociedad.

2 Se identifican como costos de manufactura a la suma de los materiales directos, con la mano de obra directa y los costos indirectos de fabricación.
} 
emanadas de las dinámicas exhibidas por la sociedad actual, los agentes que efectúan actividades manufactureras, comerciales o de servicios deben propender por la optimización de sus procesos corporativos; en este punto, la contabilidad de gestión - mediante todos sus elementos integradores-se constituye en un mecanismo técnico científico que genera información útil y pertinente para que la gerencia de las organizaciones cimente el proceso de toma de decisiones con respecto a la planeación y el control empresarial.

Por otra parte, Charles T. Horngren y George Foster (citados por Gómez-Chiñas, 2002) consideran que la contabilidad de gestión se establece como una subdivisión de la ciencia contable que propende por la ejecución de un proceso sistemático de identificación, medición, acumulación, análisis, preparación, interpretación y acumulación de información cuantitativa y cualitativa sobre la actual posición financiera de la organización, los resultados del ejercicio operacional, las capacidades de la empresa en la generación de flujos positivos de efectivo, y los cambios en la estructura patrimonial y financiera que haya experimentado el ente económico como producto de la ejecución del objeto social.

Para María Luisa Esteban-Salvador (1998), las constantes limitaciones que caracterizan la contabilidad financiera en lo concerniente al suministro de información clave para la toma de decisiones en ciertos sectores económicos — como el industrial-marcaron el surgimiento de la contabilidad de gestión como una función básica de los estamentos directivos de las organizaciones; en este sentido, la autora destaca como finalidades esenciales de esta rama de la ciencia contable servir de apoyo a la administración del ente económico en la toma de decisiones, desarrollar en los agentes encargados de la dirección empresarial las capacidades necesarias para analizar las condiciones del mercado en el cual se desenvuelven y ofrecerle a la institución los elementos imprescindibles para asegurar la consecución de objetivos corporativos de manera eficiente.

De acuerdo a lo descrito por la Asociación Española de Contabilidad y Administración (AECA) (2003), la contabilidad de gestión es una rama de la ciencia encargada de la representación de las operaciones con injerencia financiera, administrativa y social sobre las organizaciones, enfocada hacia la identificación, valoración, medición y control de la circulación interna, para generar datos que sirvan de insumo y optimicen el proceso de toma de decisiones.

En este punto, es posible afirmar que la contabilidad de gestión se forja como respuesta a las múltiples necesidades exhibidas por las organizaciones empresariales, que exigen herramientas que aporten información que vaya más allá de los datos suministrados por los estados contables básicos, que suelen utilizar solo unidades monetarias en la valoración, medición y revelación de las diferentes transacciones administrativas, financieras, comerciales y sociales ejecutadas por las empresas.

En lo concerniente a las bases de medición utilizadas por la contabilidad de gestión, se puede expresar que su enfoque trasciende los horizontes netamente monetarios utilizados por la contabilidad financiera y su ecuación contable tradicional ${ }^{3}$,

\footnotetext{
3 Típicamente, la ecuación contable se ha identificado como el resumen de los recursos de propiedad de la organización y las obligaciones que esta posee en un período determinado (Horngren, Harrison \& Smith-Bamber, 2003, p. 11).
} 
en razón a que las metodologías llevadas a cabo por esta ciencia requieren técnicas que se orientan hacia mecanismos de representación tanto cuantitativos como cualitativos, dependiendo de los fines para los cuales se estructura la información que se quiere reportar.

Para servir de apoyo a la consecución de los objetivos para los cuales fue creada la organización, la contabilidad de gestión utiliza la información generada por los distintos sub- sistemas que integran el sistema contable. Por ello, la contabilidad financiera y especialmente la contabilidad de costos se catalogan como las técnicas que integradas permiten a la contabilidad de gestión efectuar estimaciones; planear y controlar las operaciones empresariales; valorar y medir los resultados operativos; y establecer congruencias y divergencias entre lo desarrollado y lo presupuestado. La gráfica 1 muestra la conexión existente entre estos elementos.

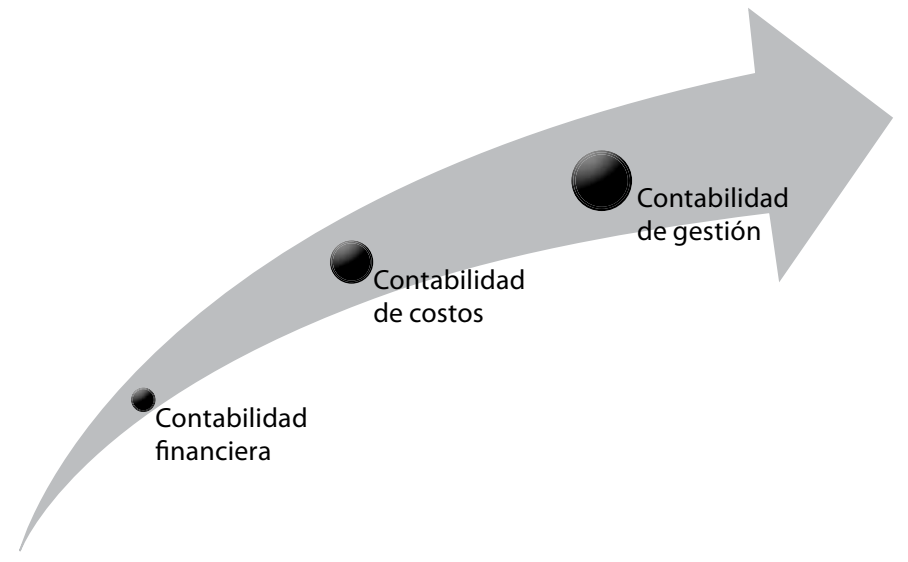

Gráfica 1

Relación existente entre los componentes del sistema contable Fuente: elaboración propia con base en Carlos Fernando Cuevas-Villegas (2001)

Desde esta perspectiva, la contabilidad de costos se cataloga como uno de los componentes más importantes de un sistema contable, en razón al papel preponderante que desempeña la determinación de las erogaciones obligatorias y necesarias en el proceso de producción y prestación de servicios cuando por medio de informes, se pretende revelar la posición financiera de la organización y sus resultados en el período operacional (Cuevas-Villegas, 2001).

\subsection{La contabilidad de costos como instrumento de gestión en las organizaciones}

En primera instancia, Ricardo Alfredo RojasMedina (2007) considera la contabilidad de costos como un sistema de información cuya finalidad se relaciona con el suministro de información útil y pertinente sobre las erogaciones en las cuales incurre una organización en el proceso de producción o en la prestación de servicios, a fin de establecer el costo de estas 
actividades; efectuar un proceso de valoración y medición de los bienes económicos que integran los activos tangibles destinados al proceso de producción o para la venta; determinar procedimientos institucionales que permitan a la organización asignar eficientemente los materiales al ciclo productivo; cimentar las bases necesarias para el cálculo del margen de utilidad y optimizar de esta manera el proceso de toma de decisiones en las empresas inmersas en la era postindustrial.

Por su parte, Gonzalo Sinisterra-Valencia y Luis Enrique Polanco-Izquierdo (2007) poseen una concepción integrativa sobre lo que representa la contabilidad de costos en el entorno empresarial actual, al afirmar que esta está constituida por técnicas y mecanismos orientados a la determinación del costo que involucra la ejecución de un proceso, la prestación de un servicio o la fabricación de un producto; no obstante, los autores anteriormente referenciados manifiestan que esta rama de la ciencia contable debe llevar a cabo una serie de actividades a fin de materializar los objetivos por los cuales se hace imperiosa su presencia en las organizaciones empresariales.

En primera instancia, se deben agrupar los elementos que integran el costo de producción ${ }^{4}$, mediante el empleo de bases de medición, utilizando para ello los datos necesarios; la segunda actividad se puede catalogar como el proceso de registro e incorporación al sistema contable de

\footnotetext{
4 Se identifican los elementos del costo como todos aquellos componentes que son necesarios para la producción de un bien o en la prestación de un servicio; de esta manera, la materia prima directa, la mano de obra directa y los costos indirectos de fabricación se catalogan como elementos del costo.
}

los valores calculados con anterioridad haciendo uso de unidades monetarias, a fin de revelar cuánto le cuestan a la organización los procesos de producción o prestación de servicios. Por otro lado, una vez los datos están explicitados por medio de los documentos e informes generados por el ciclo contable, le corresponde a la contabilidad de costos fundamentar el análisis de las tendencias y problemas en los procesos productivos para facilitar la dirección organizacional. Finalmente, exteriorizar por medio de informes claros y detallados los datos que requieran los órganos competentes de la administración, se debe reconocer como una actividad esencial de la contabilidad de costo, para efectuar el proceso de planeación y control empresarial (Sinisterra-Valencia \& Polanco-Izquierdo, 2007).

\section{Charles T. Horngren, Srikant M. Datar y} George Foster (2007) declaran que es función esencial de la contabilidad en general representar por medio de informes las diferentes transacciones y acontecimientos con injerencia financiera para la organización; desde esta perspectiva, la contabilidad de gestión mide, analiza y presenta información financiera y no financiera que apoya a la gerencia en la toma de decisiones con respecto a la consecución de los objetivos estratégicos; por otro lado, se vislumbra en la contabilidad financiera una clase de objetivos que, sin ser excluyentes, se tipifican hacia la fundamentación de las decisiones que deben ser tomadas por los distintos stakeholders ${ }^{5}$ que interactúan con el ente económico a diario.

5 Se catalogan como stakeholders los inversionistas, los banqueros, los accionistas, el Estado, el medio ambiente y la sociedad en general. 
En este escenario, la contabilidad de costos se ubica como un instrumento que, mediante herramientas y técnicas propias de esta ciencia, aporta información tanto a la contabilidad financiera como a la de gestión, a fin de que se tomen las decisiones más adecuadas tanto para los usuarios internos como para los externos.

Por último, la contabilidad de costos se cataloga como la ciencia que brinda a las organizaciones las herramientas con las cuales se propende por la transmisión de información acerca de los costos de los productos y servicios que estructuran el objeto social de la organización, utilizando para ello los distintos sistemas de gestión de costos que le son propios.

\subsection{Sistemas de gestión de costos como} herramientas para la determinación de los costos de producción

Silvana Andrea Vinza-Romero (2012) conceptúa que los sistemas de costos se erigen como un proceso corporativo con el cual se establecen distintitos lineamientos administrativos y contables, orientados hacia la identificación y caracterización de la información que se considera necesaria y relevante para la fijación del costo de los procesos, productos y servicios.

Para José Luis Carrión-Nin (2002), las causas del surgimiento de los distintos sistemas de gestión de costos se ubican en la asignación razonable de los CIF a los productos y bienes ofrecidos a la comunidad, debido a la gran relevancia que adquirieron los costos de conversión ${ }^{6}$ en los ciclos productivos tanto de las organizaciones que operaron en los sistemas

6 La suma de la mano de obra directa y los costos indirectos de fabricación se considera costo de conversión. económicos que aparecieron a partir de la revolución industrial, como de aquellas que circunscriben sus actuaciones institucionales a la actual sociedad del conocimiento, caracterizada por la constante especialización de los procedimientos corporativos, y la gran relevancia que se le ha dado al capital humano. De esta manera, en el argot empresarial se ubican dos grupos de sistemas de costos que se diferencian entre sí por las metodologías utilizadas para asignar a los costos de producción los distintos CIF que se consideran necesarios para la fabricación de los productos o en la prestación de servicios, que se catalogan como sistemas de costos tradicionales y sistemas de costos contemporáneos. La tabla 1 agrupa esta clasificación.

Por otro lado, la relevancia de la implementación de un sistema de costos - independientemente de si está entre las metodologías tradicionales o contemporáneas - reside en su capacidad de establecer la causalidad de los costos en un período determinado, lo que permite gestionar eficientemente este elemento inmerso en el proceso productivo; de igual manera, un sistema de costo proporciona a las organizaciones que operan con el contexto de la sociedad del conocimiento, las herramientas necesarias para cimentar procesos analíticos acerca de la forma en la cual se distribuyen los costos en las áreas funcionales en que están divididas.

Los diferentes teóricos que han investigado los distintos sistemas de costos utilizados por los entes económicos, presentan metodologías de asignación de las erogaciones obligatorias y necesarias en el ciclo productivo o en la prestación de servicios, que están inmersas en las técnicas sistemáticas típicamente refe- 
renciadas como tradicionales; estos estándares encuentran una taxonomía de acuerdo a la fecha en la cual se determinan los costos; dependiendo del régimen de la producción uti- lizado por la organización y tomando como referencia la forma en la cual se integran los costos al producto (Jaimes, 2006).

\begin{tabular}{|c|c|c|c|}
\hline \multicolumn{4}{|c|}{ Clasificación de los sistemas de costos } \\
\hline $\begin{array}{c}\text { Sistemas } \\
\text { de costos } \\
\text { tradicionales }\end{array}$ & $\begin{array}{l}\text { Autores que lo } \\
\text { soportan }\end{array}$ & $\begin{array}{l}\text { Sistemas de costos } \\
\text { contemporáneos }\end{array}$ & Autores que lo soportan \\
\hline $\begin{array}{l}\text { De acuerdo a la } \\
\text { fecha en la cual se } \\
\text { obtiene el costo: } \\
\text { Sistema de costos } \\
\text { histórico } \\
\text { Sistema de costos } \\
\text { predeterminados } \\
\text { (estándar y } \\
\text { estimado) }\end{array}$ & $\begin{array}{l}\text { Zulma Yadira Alvarado- } \\
\text { Mazariegos (2011) } \\
\text { Joaquín Cuervo-Tafur, Jair } \\
\text { Albeiro Osorio-Agudelo } \\
\text { y María Isabel Duque- } \\
\text { Roldán (2007) } \\
\text { Carlos Fernando Cuevas- } \\
\text { Villegas (2001) } \\
\text { David Noel Ramírez- } \\
\text { Padilla (2005) } \\
\text { Salvador Mercado (1997) } \\
\text { Ernesto Reyes-Pérez } \\
\text { (2005) }\end{array}$ & Target Costing & Armando Jaimes-Cruz (2006) \\
\hline $\begin{array}{l}\text { En atención al } \\
\text { régimen de la } \\
\text { producción: } \\
\text { Órdenes de } \\
\text { producción } \\
\text { Sistema de costos } \\
\text { por procesos }\end{array}$ & $\begin{array}{l}\text { Gastón Peterson-Véjar } \\
\text { (2002) } \\
\text { Ralph S. Polimeni, Frank } \\
\text { J. Fabozzi y Arthur H. } \\
\text { Adelberg (1997) } \\
\text { Ricardo Alfredo Rojas- } \\
\text { Medina (2007) }\end{array}$ & Kaizen Costing & Carlos Fernando Cuevas-Villegas (2002) \\
\hline $\begin{array}{l}\text { En atención a la } \\
\text { forma de integrar el } \\
\text { costo: } \\
\text { Costeo directo } \\
\text { Costeo absorbente }\end{array}$ & $\begin{array}{l}\text { Francisco Jiménez- } \\
\text { Boulanger y Carlos Luis } \\
\text { Espinoza-Gutiérrez } \\
\text { (2007) } \\
\text { Bernard J. Hargadon } \\
\text { y Armando Múnera- } \\
\text { Cárdenas (1996) }\end{array}$ & $\begin{array}{l}\text { Activity Based Costing } \\
(\mathrm{ABC})\end{array}$ & $\begin{array}{l}\text { Jorge Caldera, Pilar Baujín-Pérez, Vicente } \\
\text { Ripoll-Feliu y Vladimir Vega-Falcón } \\
\text { (2007) } \\
\text { Thomas Johnson y Robert S. Kaplan } \\
\text { (1988) } \\
\text { Robert S. Kaplan y Robin Cooper (2000) } \\
\text { Jeffrey G. Miller y Thomas E. Vollmann } \\
\text { (1985) } \\
\text { Michael Porter (1985) } \\
\text { George J. Staubus (1971) }\end{array}$ \\
\hline
\end{tabular}

Tabla 1

Clasificación de los sistemas de costos

Fuente: elaboración propia 
Francisco Jiménez-Boulanger y Carlos Luis Espinoza-Gutiérrez (2007) argumentan que la característica fundamental de los sistemas de costos catalogados como tradicionales es la utilización de tasas predeterminadas ${ }^{7}$ o coeficientes reguladores, a fin de asignar de manera razonable los CIF y poseer bases unitarias de actividad con las cuales se faciliten la medición y el control del desempeño empresarial.

Por otro lado, Jorge Caldera, Pilar BaujínPérez, Vicente Ripoll-Feliu y Vladimir VegaFalcón (2007) argumentan que la creciente internacionalización de la cultura, la política y la economía generaron en las organizaciones la creciente necesidad de utilizar procedimientos que se enfocaran en la búsqueda de la alta calidad, la optimización del servicio al cliente, la formación continua del capital humano y la reducción de costos; ante estas exigencias, los sistemas de costos catalogados como tradicionales exhibieron fuertes falencias en razón a que estos estándares estaban relacionados con el volumen de la producción, segando las operaciones empresariales por ser de visión interna.

Estas situaciones trajeron el surgimiento de nuevos estándares de asignación de costos acordes con las exigencias provenientes de los mercados inmersos en los sistemas económicos

7 Teresa de Jesús Altahona-Quijano (2009) resalta que para el cálculo de las tasas predeterminadas, se toman como referencia los costos indirectos de fabricación presupuestados en el período contable que generalmente es mensual o anual, divididos entre el nivel de producción presupuestado expresado de acuerdo a la base tomada en el proceso de producción; se resaltan como las bases más usuales en el ciclo productivo en una organización las siguientes: horas de mano de obra directa (horas hombre), valor mano de obra (valor horas hombre), horas máquina, costos de los materiales directos, entre otras. pertenecientes a la sociedad postindustrial; de este modo, Ángel Sáez-Torrecilla (citado por Möller, 2011) destaca una lista de modelos de gestión del costo que se han acordado en llamar sistemas contemporáneos, por constituir herramientas de control de calidad en los procesos con los cuales las empresas asignan los costos de producción a los bienes, ya sean de naturaleza tangible o intangible. De esta manera, se ubican bajo esta taxonomía el sistema de costo Target Costing, el Kaizen Costing (JIT) y el Activity Based Costing (ABC).

De los sistemas de gestión orientados a la medición, valoración y control de las erogaciones obligatorias y necesarias en el ciclo de producción explicitados anteriormente, el que se ha revestido de especial trascendencia en las organizaciones inmersas en la era postindustrial es el Sistema de Costos Basado en Actividades $(\mathrm{ABC})$, en razón a las características de las metodologías y técnicas utilizadas para la asignación de los CIF a los costos de producción.

\subsection{Fundamentos teóricos doctrinales del sistema de costos $A B C$}

Los fundamentos teóricos del sistema de costos $\mathrm{ABC}$ se ubican en los aportes efectuados por George J. Staubus (1971), quien establece las bases conceptuales referentes a la estructuración de las operaciones organizacionales por medio de tareas; Michael Porter (1985), mediante la conformación de la teoría de la cadena de valor; y en lo descrito por Jeffrey G. Miller y Thomas E. Vollmann (1985), al instituir una metodología integrativa con la teoría de la cadena de valor, que sirvió de base para la determinación de los principios del sistema de costos $\mathrm{ABC}$. 
Sin embargo, los primeros teóricos que cuestionaron la eficacia de los sistemas de costos tradicionales - como herramienta esencial en la fundamentación de la toma de decisiones financieras por estar enfocados hacia la valoración de los inventarios y, por ende, los causantes del deterioro y estancamiento del nivel de productividad en países como Estados Unidosfueron Thomas Johnson y Robert S. Kaplan (1988) en su libro La contabilidad de costes: auge y caída de la contabilidad de gestión.

Estos autores enfocaron su interés en los constantes cambios que se estaban presentando en el ciclo productivo y en la forma en que las organizaciones establecían las condiciones necesarias para que los productos estuvieran en condiciones óptimas para intercambiarse en el mercado, en la búsqueda de nuevos sistemas de gestión con los cuales la determinación de los costos fuera más acorde con las exigencias de la economía.

De esta manera, presentaron un sistema de gestión empresarial con el cual las organizaciones podrían cimentar las decisiones estratégicas en cuanto al establecimiento de cuáles aspectos relativos a los clientes y productos o servicios generan rentabilidad a la empresa, qué inversiones realizar en toda la cadena de valor establecida en el ente económico y poder reducir costos con base en las actividades y procesos y en la determinación de las actividades que no generan valor agregado para la organización y así fundamentar su eliminación o reclasificación.

Para lograr cumplir los objetivos planteados, el Sistema de Costos Basado en Actividades $(\mathrm{ABC})$, propuesto por Thomas Johnson y Ro- bert S. Kaplan (1988), posee como tesis central que el proceso de producción de bienes y la prestación de servicios involucra la materialización de ciertas actividades que se consideran necesarias para llevarlos a cabo; así mismo, estas actividades o transacciones causan erogaciones necesarias y obligatorias en la consecución del objeto social de la organización. Por esta razón, los entes económicos deben propender por la ejecución del presupuesto tomando como referencia las actividades necesarias en el ciclo operacional, de acuerdo a lo especificado por Michael Porter (1985).

Nidia Lisseth Guevara-Carbajal, Jaime Alejandro Ramírez-Lemus y Bruno Paul Alexander Vásquez (2010) exponen que la verdadera importancia del sistema de costos $\mathrm{ABC}$ está relacionada con la definición de nuevas herramientas para la asignación de los CIF, de acuerdo a la realidad económica, administrativa y social de la organización; se enfatiza que este método genera datos de mayor razonabilidad en razón a que estructura la institución mercantil en procedimientos básicos, con el fin de caracterizar cuáles son las actividades elementales para llevar a cabo el objeto social de la empresa y determinar de esta manera cuál de ellas genera valor.

De otra parte, si una organización desea asignar los costos de acuerdo a las metodologías impuestas por el sistema de costos $\mathrm{ABC}$, es relevante que esté constituida por las actividades necesarias para desarrollar su objeto social; en este sentido, las actividades van a describir lo que realiza el ente económico; sin embargo, bajo la tesis planteada por el sistema de costos $\mathrm{ABC}$, para lograr entender qué significa el concepto de actividad bajo el contexto organizacional, es necesario 
saber que esta parte de un proceso en el cual una entrada acciona la ejecución de la actividad, para luego consumir los recursos necesarios para llevarla a cabo (Zapata-Sánchez, 2007).

\section{Aspectos metodológicos}

Con la finalidad esencial de darle cumplimiento al objetivo que dirimió el presente artículo y apoyados en lo que expresa Marcelo M. Gómez (2006), la investigación efectuada tuvo un enfoque cuantitativo, debido a que se utilizaron las herramientas aportadas por la estadística descriptiva y diferencial, a fin de materializar los propósitos establecidos; de otra parte y tomando en consideración lo argumentado por Hugo Cerdá-Gutiérrez (1995), el alcance del estudio ejecutado se relacionó con el descriptivo y se manejó como método de estudio el deductivo, definido por César Augusto Bernal-Torres (2006) como "un método de razonamiento para obtener conclusiones generales para explicaciones particulares, el método se inicia con el análisis de postulados, teoremas, leyes, principios, etc. De aceptación universal y de comprobada validez para aplicarlos a soluciones o hechos particulares" (p. 56).

En lo concerniente a las estrategias definidas a fin de recolectar la información útil y pertinente para la materialización del estudio, se puede expresar que se utilizó el diseño de investigación no experimental correlacional causal, en razón a que se observaron los fenómenos y las variables tal como se dan en su contexto natural, con el objeto de analizarlos (Hernández-Sampieri, Fernández-Collado \& Baptista-
Lucio, 2006, p. 245). Como consecuencia de esto, están fundamentadas en analizar las características de los fenómenos y variables de estudio en el contexto en el cual se desenvuelven, por lo tanto, en el presente trabajo de investigación se seleccionaron aquellos factores predominantes en la toma de decisiones "sistemas de costos" para luego medirlos y expresar la situación actual en las cooperativas de ahorro y crédito de la ciudad de Barranquilla.

La población estuvo definida por el conjunto de cooperativas de ahorro y crédito pertenecientes a la ciudad de Barranquilla. Con referencia al muestreo probabilístico aleatorio simple, en razón a que todos los elementos pertenecientes a la población tienen la misma probabilidad de ser incluidos en la muestra, su inclusión no está influenciada por otros componentes y todas las muestras pueden formarse con elementos de la población (Gómez, 2006, p. 113). Se definió como instrumento de recolección de la información primaria la encuesta Likert, que se dirigió a las cooperativas de ahorro y crédito de Barranquilla, determinadas por muestreo probabilístico aleatorio simple (Hernández-Sampieri, Fernández-Collado \& Baptista-Lucio, 2006).

\section{Resultados de la investigación}

El presente acápite integra los resultados arrojados por el instrumento de recolección de información primaria, que permite identificar los sistemas de gestión de costos tradicionales utilizados en las cooperativas de ahorro y crédito de Barranquilla y los problemas que 
afrontan los agentes encargados de efectuar este proceso en las instituciones antes mencionadas, al cimentar la toma de decisiones financieras, y que recurren a la metodología $\mathrm{ABC}$ como una opción eficiente para fundamentar este proceso.

En primera instancia, es conveniente resaltar que de la muestra estudiada el 70\% ha manifestado poseer algún procedimiento sistemático de naturaleza administrativa y contable para la valoración de los procesos ejecutados o en la estimación del costo de los servicios ofrecidos a la sociedad; por el contrario, el 20\% de los funcionarios inmersos en los departamentos contables de las cooperativas objeto de estudio, sostuvo que en las instituciones en donde trabajan, la utilización de procedimientos sistemáticos para la asignación de los costos no es una estrategia corporativa (tabla 2).

\begin{tabular}{lcc}
\hline Respuesta & $\begin{array}{c}\text { Frecuencia } \\
\text { (veces) }\end{array}$ & $\begin{array}{c}\text { Porcentaje } \\
\text { (\%) }\end{array}$ \\
\hline Sí & 56 & 70 \\
No & 16 & 20 \\
No contestó & 8 & 10 \\
\hline Total & 80 & 100 \\
\hline
\end{tabular}

Tabla 2

Procedimiento sistemático de naturaleza administrativa y contable para identificar la información necesaria y pertinente

Fuente: resultados de la encuesta aplicada (2013)

Una vez aplicado el instrumento, se logró determinar que las cooperativas que ejercen actividades financieras en la ciudad de Barranquilla se caracterizan por manejar herramientas de gestión para calcular el costo de los servicios, procesos y productos, utilizando para este fin procedimientos sistemáticos de naturaleza contable y administrativa, lo que les permite a esas organizaciones establecer estrategias de control sobre los servicios y productos que ofrece a la sociedad.

Entre los procedimientos orientados al cálculo de las erogaciones necesarias y obligatorias en las cooperativas estudiadas, está el sistema de costos que utiliza como base de medición el valor de los desembolsos relacionados con la producción, una vez estos se han realizado. Por otro lado, el sistema de costos estándar - entendido este como aquel que utiliza estudios estadísticos para determinar el costo de los procesos, servicios y productos con antelación a su ejecución-se presenta como instrumento de gestión en las organizaciones cooperativistas de Barranquilla con un menor porcentaje de participación; estas consideraciones se pueden constatar en la tabla 3.

\subsection{Los sistemas de costos tradicionales utilizados por las cooperativas de ahorro y crédito de Barranquilla y sus efectos en la toma de decisiones}

Inicialmente, para el 74,6\% de los funcionarios encuestados, la información generada por el sistema de costos utilizado por la institución a la cual pertenecen no posee las herramientas necesarias para generar insumos útiles y pertinentes para cimentar el proceso de toma de decisiones; ante esta situación, el 12,5\% considera que el procedimiento utilizado por la institución no presenta mayores problemas en el apoyo de la dirección empresarial en sus etapas de planeación, control y decisión (tabla 4). 


\section{2 / VOL. 17 / NO. 44 / JULIO-DICIEMBRE 2016}

\begin{tabular}{|c|c|c|c|c|c|c|}
\hline Afirmación & TD (\%) & DA (\%) & $\begin{array}{l}\text { IND } \\
(\%)\end{array}$ & ED (\%) & TE (\%) & $\begin{array}{l}\text { Porcentaje de } \\
\text { aceptación (\%) }\end{array}$ \\
\hline $\begin{array}{l}\text { La característica principal del sistema } \\
\text { de costos utilizado en la cooperativa se } \\
\text { representa en que la base de medición } \\
\text { utiliza la obtención de los costos reales } \\
\text { después de que el servicio se ha prestado. }\end{array}$ & 25,0 & 37,5 & 6,3 & 17,5 & 13,8 & 62,5 \\
\hline $\begin{array}{l}\text { El fundamento esencial del sistema } \\
\text { de costo utilizado en la cooperativa se } \\
\text { representa en el cálculo del costo de los }\end{array}$ & & & & & & \\
\hline $\begin{array}{l}\text { servicios prestados con antelación al } \\
\text { inicio del período productivo, con base } \\
\text { en estudios estadísticos previamente } \\
\text { realizados por profesionales idóneos. }\end{array}$ & 12,5 & 18,8 & 6,3 & 50,0 & 12,5 & 31,3 \\
\hline $\begin{array}{l}\text { Los costos unitarios de los servicios } \\
\text { prestados por la cooperativa se } \\
\text { determinan a partir de órdenes } \\
\text { específicas tomando como referencia las } \\
\text { necesidades individuales de los asociados. }\end{array}$ & 0,0 & 0,0 & 6,2 & 58,8 & 35,0 & 0,0 \\
\hline $\begin{array}{l}\text { La cooperativa está segregada por } \\
\text { procesos o departamentos y los costos } \\
\text { se acumulan sobre cada uno de ellos } \\
\text { tomando como base una unidad de } \\
\text { tiempo, que se traslada de proceso en } \\
\text { proceso hasta su terminación. }\end{array}$ & 0,0 & 0,0 & 11,3 & 40,0 & 48,8 & 0,0 \\
\hline
\end{tabular}

Tabla 3

Sistemas de costos en las cooperativas de ahorro y crédito ubicadas en la ciudad de Barranquilla ${ }^{8}$ Fuente: resultados de la encuesta aplicada (2013)

\begin{tabular}{|c|c|c|c|c|c|}
\hline & Rango & $\begin{array}{l}\text { Frecuencia } \\
\text { (veces) }\end{array}$ & $\begin{array}{c}\text { Porcentaje } \\
(\%)\end{array}$ & $\begin{array}{l}\text { Porcentaje } \\
\text { válido (\%) }\end{array}$ & $\begin{array}{c}\text { Porcentaje } \\
\text { acumulado (\%) }\end{array}$ \\
\hline \multirow{6}{*}{ Válidos } & $\begin{array}{l}\text { Totalmente en } \\
\text { desacuerdo }\end{array}$ & 4 & 5,0 & 5,0 & 5,0 \\
\hline & En desacuerdo & 6 & 7,5 & 7,5 & 12,5 \\
\hline & Indiferente & 4 & 5,0 & 5,0 & 17,5 \\
\hline & De acuerdo & 47 & 58,8 & 58,8 & 76,3 \\
\hline & $\begin{array}{l}\text { Totalmente de } \\
\text { acuerdo }\end{array}$ & 19 & 23,8 & 23,8 & 100,0 \\
\hline & Total & 80 & 100,0 & 100,0 & \\
\hline
\end{tabular}

Tabla 4

La información generada por el sistema de costo utilizado por la cooperativa no permite soportar el proceso de toma de decisiones

Fuente: resultados de la encuesta aplicada (2013)

8 TD: totalmente de acuerdo. DA: de acuerdo. IND: indiferente. ED: en desacuerdo. TE: totalmente en desacuerdo. 
Los resultados demostrados anteriormente son congruentes con lo expresado por el $87,6 \%$ de los encuestados, en razón a que para ellos el sistema de costos utilizado en la cooperativa en la cual trabajan, presenta un alto grado de dificultad para proporcionar información exac- ta sobre el margen de utilidad de los servicios ofrecidos a la sociedad; en este caso, el 5,0\% de los funcionarios pertenecientes a la muestra afirma lo contrario; por último, un 7,5\% de los empleados encuestados no emitió opinión alguna (gráfica 2).

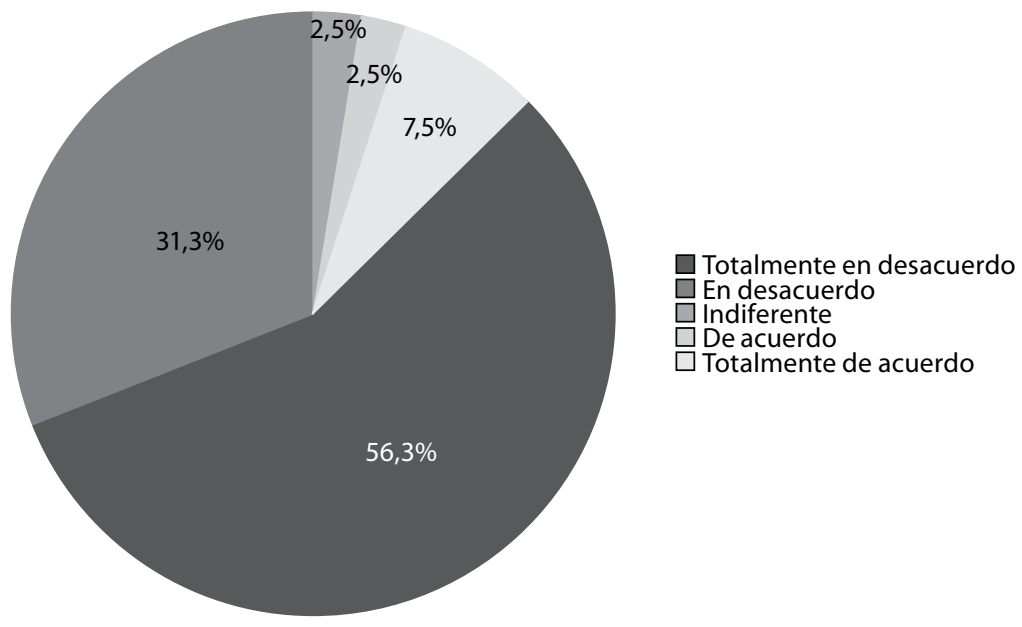

Gráfica 2

El sistema de costos utilizado en la cooperativa presenta dificultad para proporcionar información exacta sobre el margen de utilidad en el servicio prestado

Fuente: resultados de la encuesta aplicada (2013)

De otra parte, para el $75 \%$ de los funcionarios del departamento encargado de la identificación, valoración y revelación de las operaciones con injerencia financiera en las organizaciones solidarias estudiadas, el sistema de costos utilizado no proporciona datos claves de naturaleza financiera y no financiera con los cuales se pueden determinar las causas y el comportamiento de los CIF; ante esta afirmación, el 12,5\% de los encuestados considera que los procesos definidos para acumular los costos genera información relevante acerca de los CIF; el restante 12,5\% fue neutral ante la afirmación planteada (tabla 5).
En lo concerniente a las capacidades del sistema de costos utilizado por la cooperativa en el suministro de datos útiles y relevantes para conocer la composición de los costos que se incorporan a los procesos y de esta manera ejecutar comparaciones coherentes y homogéneas, los resultados demuestran en un $75 \%$ que el proceso sistemático utilizado por las instituciones solidarias objeto de estudio, no posee las características necesarias para establecer la estructura y el comportamiento de las erogaciones obligatorias y necesarias para la prestación de los servicios característicos de la institución 
hacia la sociedad, situación que no permite sustentar la toma de decisiones mediante el suministro de información relevante. En este caso, un $15,1 \%$ de la muestra afirmó lo contrario, mientras que el 10\% se abstuvo de emitir opinión alguna (gráfica 3).

\begin{tabular}{llcccc}
\hline Rango & $\begin{array}{c}\text { Frecuencia } \\
\text { (veces) }\end{array}$ & $\begin{array}{c}\text { Porcentaje } \\
\text { (\%) }\end{array}$ & $\begin{array}{c}\text { Porcentaje } \\
\text { válido (\%) }\end{array}$ & $\begin{array}{c}\text { Porcentaje } \\
\text { acumulado (\%) }\end{array}$ \\
\hline \multirow{6}{*}{ Válidos } & 10 & 12,5 & 12,5 & 12,5 \\
& Totalmente en & & & 12,5 & 25,0 \\
& desacuerdo & 10 & 12,5 & 50,0 & 75,0 \\
& Indiferente & 40 & 50,0 & 25,0 & 100,0 \\
\cline { 2 - 6 } & De acuerdo & 20 & 25,0 & 100,0 & \\
\cline { 2 - 6 } & Totalmente de acuerdo & 100,0 & &
\end{tabular}

Tabla 5

El sistema de costo utilizado por la cooperativa no proporciona datos claves no financieros que permitan establecer las causas y el comportamiento de los CIF

Fuente: resultados de la encuesta aplicada (2013)

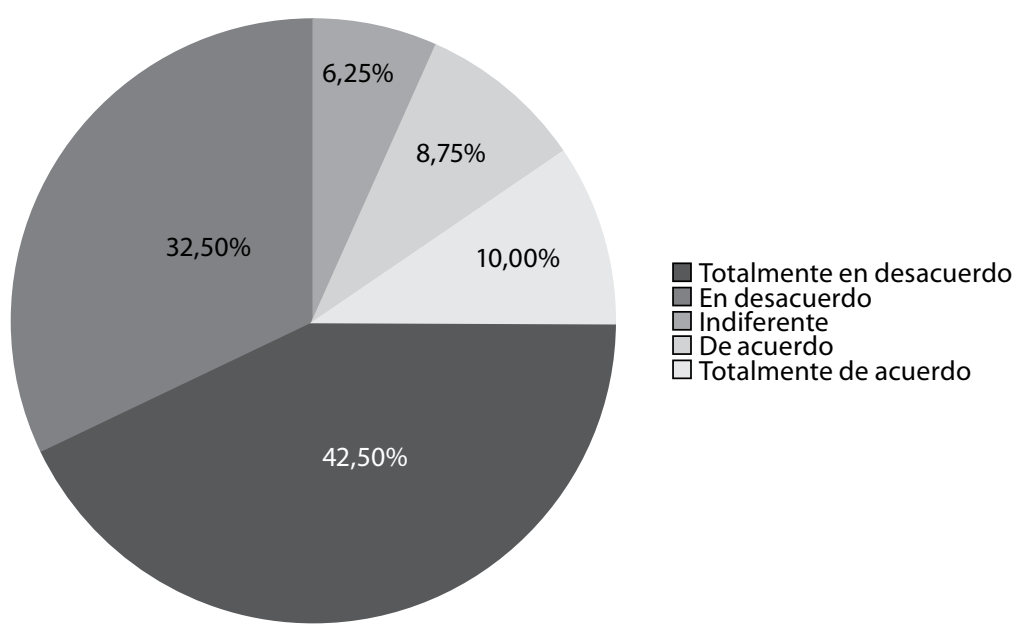

Gráfica 3

El sistema de costos utilizado por la cooperativa no permite conocer la composición de los costos que se incorporan a los procesos, razón por la cual no se pueden hacer comparaciones coherentes y homogéneas Fuente: resultados de la encuesta aplicada (2013)

De acuerdo a la teoría expuesta por Michael Porter (1985), las organizaciones deben propender por la identificación de los distintos procesos que integran su estructura empresarial que generan valor y sostenibilidad en el mercado; en este sentido, se pudo determinar mediante la aplicación del instrumento de recolección de información primaria, que los procedimientos de naturaleza administrativa y contable orientados a la determinación de los costos en los 
cuales se incurre en la prestación de servicios a la sociedad, no permiten identificar cuál de ellos representa para la organización solidaria la generación de valor agregado; esta disposición es avalada por el 62,5\% de los funcionarios encuestados (tabla 6).

\begin{tabular}{llcccc}
\hline Rango & $\begin{array}{c}\text { Frecuencia } \\
\text { (veces) }\end{array}$ & $\begin{array}{c}\text { Porcentaje } \\
\text { (\%) }\end{array}$ & $\begin{array}{c}\text { Porcentaje } \\
\text { válido (\%) }\end{array}$ & $\begin{array}{c}\text { Porcentaje } \\
\text { acumulado (\%) }\end{array}$ \\
\hline \multirow{4}{*}{ Válidos } & 19 & 23,8 & 23,8 & 23,8 \\
& Totalmente en & & 38,8 & 38,8 & 62,5 \\
& desacuerdo & 31 & 3,8 & 3,8 & 66,3 \\
& En desacuerdo & 3 & 17,5 & 17,5 & 83,8 \\
& Indiferente & 14 & 16,3 & 16,3 & 100,0 \\
& De acuerdo & & & & \\
& Totalmente de & 13 & 100,0 & 100,0 & \\
& acuerdo & 80 & & &
\end{tabular}

Tabla 6

La estructura de los procesos que hacen parte del ciclo operacional del ente económico permite determinar cuál de ellos está generando valor al servicio prestado

Fuente: resultados de la encuesta aplicada (2013)

En cuanto a las capacidades organizacionales para la identificación de los procesos claves de la institución, los resultados arrojan que el $58,8 \%$ de la muestra objeto de estudio manifiesta que en las instituciones solidarias que practican actividades de ahorro y crédito como gran parte de su objeto social en la ciudad de Barranquilla, la estructura de los procedimientos institucionales no permite precisar cuáles son las diferentes actividades que integran la cadena de valor de la institución (gráfica 4).

\subsection{Metodología ABC como una opción eficiente para fundamentar el proceso de toma de decisiones en las cooperativas de ahorro y crédito}

En las organizaciones solidarias del cooperativismo, el sistema de costos $\mathrm{ABC}$ es una excelente alternativa con la cual se pueden tomar decisiones con un alto grado de eficiencia acerca de los productos de naturaleza tangible e in- tangible ofrecidos al mercado, en razón a que proporciona datos claves de naturaleza financiera y no financiera con los cuales se pueden determinar las causas y el comportamiento de los costos indirectos de fabricación. Lo anterior se fundamenta en que esta metodología de asignación de costos facilita la adquisición de conocimiento útil y necesario acerca de la estructura de las entidades que integran el sector cooperativista que desarrollan actividades de ahorro y crédito.

En consecuencia, la metodología del sistema de costos $\mathrm{ABC}$ se podría considerar como un instrumento estratégico con el cual las cooperativas podrían suplir las deficiencias de su estructura organizacional que no les permiten poseer pleno conocimiento de sus actividades; la siguiente tabla demuestra las falencias de los procedimientos institucionales utilizados por estas instituciones para generar datos útiles y relevantes para la adquisición de conocimiento 


\section{6 / VOL. $17 /$ / NO. 44 / JULO-DICEEMBR 2016}

organizativo referente a los procesos que conforman la cadena de valor de las organizaciones solidarias objeto de estudio, debido a que el
$62,5 \%$ de la muestra estudiada considera que los procesos internos de las instituciones a las cuales pertenecen tienen falencias (tabla 7).

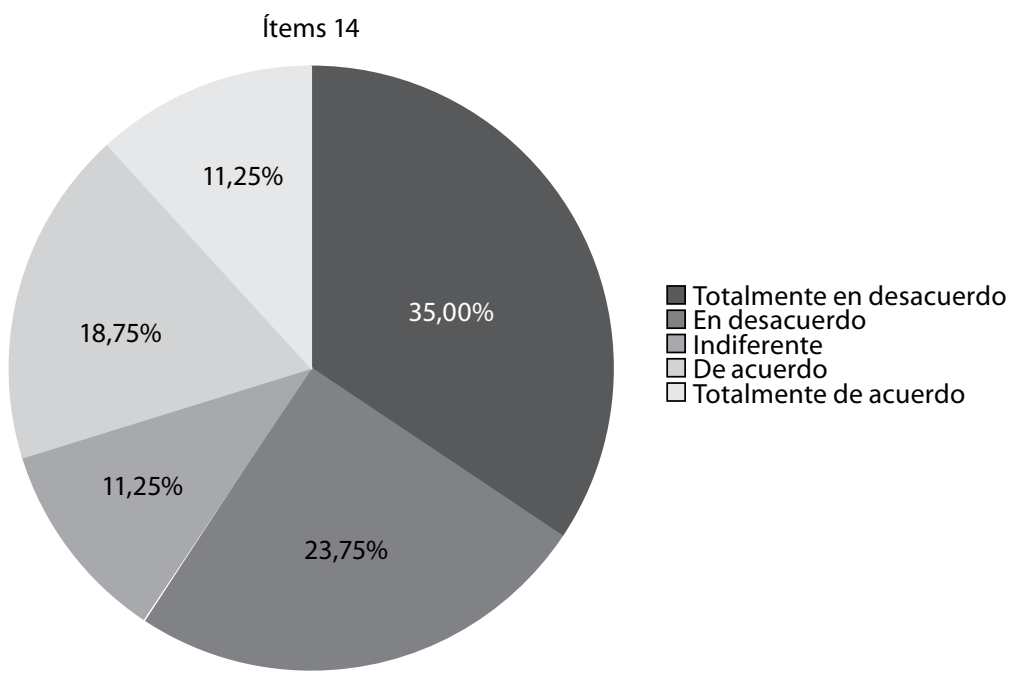

Gráfica 4

La estructura de los procesos claves del ente económico permite establecer cuáles son las actividades que conforman cada uno de ellos

Fuente: resultados de la encuesta aplicada (2013)

\begin{tabular}{|c|c|c|c|c|c|}
\hline & Rango & $\begin{array}{l}\text { Frecuencia } \\
\text { (veces) }\end{array}$ & $\begin{array}{l}\text { Porcentaje } \\
\text { (\%) }\end{array}$ & $\begin{array}{l}\text { Porcentaje } \\
\text { válido (\%) }\end{array}$ & $\begin{array}{c}\text { Porcentaje } \\
\text { acumulado (\%) }\end{array}$ \\
\hline \multirow{6}{*}{ Válidos } & $\begin{array}{l}\text { Totalmente en } \\
\text { desacuerdo }\end{array}$ & 24 & 30,0 & 30,0 & 30,0 \\
\hline & En desacuerdo & 26 & 32,5 & 32,5 & 62,5 \\
\hline & Indiferente & 15 & 18,8 & 18,8 & 81,3 \\
\hline & De acuerdo & 10 & 12,5 & 12,5 & 93,8 \\
\hline & $\begin{array}{l}\text { Totalmente de } \\
\text { acuerdo }\end{array}$ & 5 & 6,3 & 6,3 & 100,0 \\
\hline & Total & 80 & 100,0 & 100,0 & \\
\hline
\end{tabular}

Tabla 7

Se posee pleno conocimiento de las actividades necesarias en las cooperativas Fuente: resultados de la encuesta aplicada (2013)

Por otra parte, la aplicación del instrumento de recolección de información primaria a las instituciones solidarias del cooperativismo que ejercen actividades de ahorro y crédito en la ciudad de Barranquilla, permitió establecer que para el 70\% de las instituciones abordadas, la asignación de los CIF tomando como referencia los recursos consumidos por las 
actividades, generaría mayor eficiencia en la obtención del valor de los productos y en la mejora de los procesos. Vale mencionar que esta es una de las características primordia- les que catapultaron el sistema de costos $\mathrm{ABC}$ como el procedimiento de asignación de costos de mayor relevancia en la actualidad (gráfica 5).

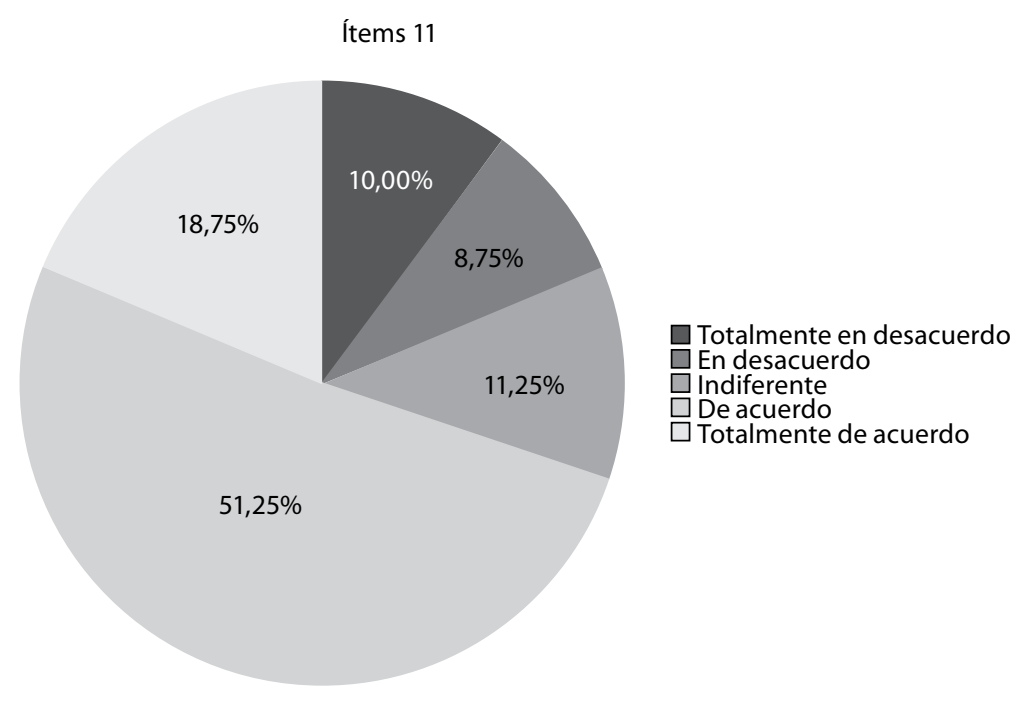

\section{Gráfica 5}

La asignación de los CIF tomando como referencia los recursos consumidos por las actividades generaría mayor eficiencia en la obtención del valor de los productos y en la mejora de los procesos

Fuente: resultados de la encuesta aplicada (2013)

De igual manera, con la técnica de recolección de información primaria se logró determinar que para el 25\% de los funcionarios encuestados el sistema de costos $\mathrm{ABC}$ es flexible a las necesidades de la cooperativa y se orienta a lograr el liderazgo de la institución, en razón a que utiliza indicadores financieros y no financieros; ante esta afirmación, el 50\% de los encuestados se ubicó en una postura indiferente, lo cual muestra la falta de capacitación y cualificación por parte de los funcionarios dedicados a la identificación, medición y valoración de las transacciones comerciales y sociales de la institución, acerca de las metodologías del sistema de costos ABC (tabla 8).
La efectividad y eficiencia de los sistemas de costos basados en actividades se relaciona con las posibilidades que brinda este estándar para asignar las erogaciones obligatorias y necesarias al proceso de producción o a la prestación de servicios, para la elaboración de la lista de las actividades que generan valor a la organización y de esta manera orientarlas a la determinación del grado de consumo de los CIF en cada una de ellas; en este caso, el 75\% de la muestra encuestada está de acuerdo en que la definición de las actividades necesarias para la consecución del objeto social de la organización es un aspecto 
relevante para que la organización genere valor agregado a partir de la correcta asig- nación de las cargas fabriles que consumen cada una de ellas (gráfica 8).

\begin{tabular}{llcccc}
\hline Rango & $\begin{array}{c}\text { Frecuencia } \\
\text { (veces) }\end{array}$ & $\begin{array}{c}\text { Porcentaje } \\
\text { (\%) }\end{array}$ & $\begin{array}{c}\text { Porcentaje } \\
\text { válido (\%) }\end{array}$ & $\begin{array}{c}\text { Porcentaje } \\
\text { acumulado (\%) }\end{array}$ \\
\hline \multirow{2}{*}{$\begin{array}{l}\text { Totalmente en } \\
\text { desacuerdo }\end{array}$} & 8 & 10,0 & 10,0 & 10,0 \\
& En desacuerdo & 12 & 15,0 & 15,0 & 25,0 \\
& Indiferente & 40 & 50,0 & 50,0 & 75,0 \\
& De acuerdo & 10 & 12,5 & 12,5 & 87,5 \\
& Totalmente de & 10 & 12,5 & 12,5 & 100,0 \\
\hline & acuerdo & 80 & 100,0 & 100,0 & \\
\hline
\end{tabular}

Tabla 8

El sistema de costos $\mathrm{ABC}$ es flexible a las necesidades de la cooperativa y orientado a lograr el liderazgo en razón a que utiliza indicadores financieros y no financieros Fuente: resultados de la encuesta aplicada (2013)

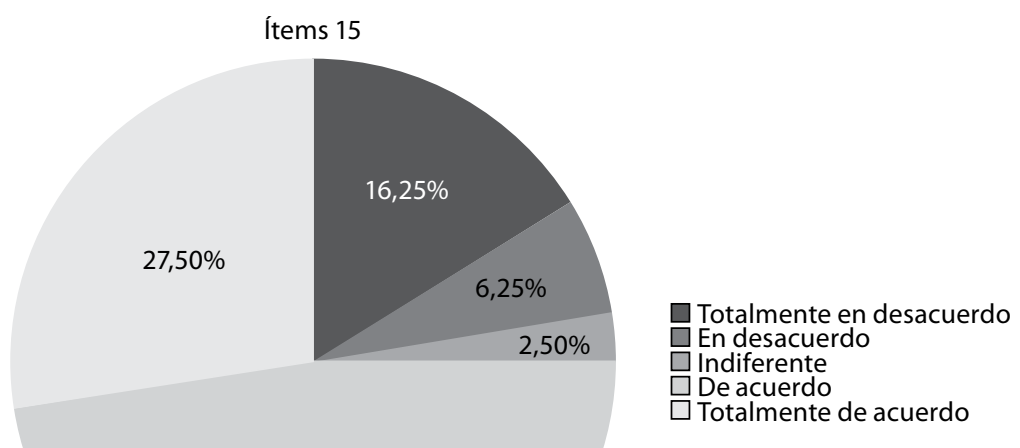

$47,50 \%$

\section{Gráfica 6}

La elaboración de la lista de las actividades que generan valor a la organización es necesaria para asignar el grado de consumo de CIF en cada una de ellas

Fuente: resultados de la encuesta aplicada (2013) 
Otra de las características de mayor trascendencia del sistema de costos basado en actividades es la utilización de bases de asignación de los CIF que toman como referencia tanto el volumen de la producción como las actividades que estructuran los procesos organizacionales, motivo por el cual la información generada por este estándar tiene un alto nivel de exactitud en la fundamentación de la toma de decisiones; para el 60\% de las instituciones cooperativas que constituyeron la muestra estudiada, la implementación de un sistema de costos que posea estas características constituye una herra- mienta relevante para la cimentación del proceso decisorio en estas instituciones (tabla 9).

Finalmente, el 65,1\% de las cooperativas de ahorro y crédito que operan en la ciudad de Barranquilla considera perentoria la implementación de un sistema de costos basado en actividades, en razón a que generaría información ostensiblemente más acorde con la realidad de las operaciones efectuadas por las organizaciones anteriormente mencionadas; de otra parte, esta afirmación se justifica por la confiabilidad de los datos suministrados para cimentar el proceso de toma de decisiones (gráfica 7).

\begin{tabular}{llcccc}
\hline Rango & $\begin{array}{c}\text { Frecuencia } \\
\text { (veces) }\end{array}$ & $\begin{array}{c}\text { Porcentaje } \\
\text { (\%) }\end{array}$ & $\begin{array}{c}\text { Porcentaje } \\
\text { válido (\%) }\end{array}$ & $\begin{array}{c}\text { Porcentaje } \\
\text { acumulado (\%) }\end{array}$ \\
\hline \multirow{6}{*}{ Válidos } & 7 & 8,8 & 8,8 & 8,8 \\
& Totalmente en & & 28,7 & 28,7 & 37,5 \\
& desacuerdo & 23 & 2,5 & 2,5 & 40,0 \\
& Indesacuerdo & 2 & 35,0 & 35,0 & 75,0 \\
& De acuerdo & 28 & 25,0 & 25,0 & 100,0 \\
& Totalmente de acuerdo & 20 & 100,0 & 100,0 & \\
\cline { 2 - 6 } & Total & 80 & & & \\
\hline
\end{tabular}

Tabla 9

La implementación de un sistema de costos que utilice como base de asignación de los CIF referencias basadas en el volumen de producción y en aquellas relacionadas con las actividades generaría información con un mayor grado de exactitud para la toma de decisiones

Fuente: resultados de la encuesta aplicada (2013)

\section{En otras ciudades de América Latina}

Las cooperativas de América Latina presentan diversos orígenes, antigüedad, tamaño, oferta de productos, estructuras organizativas, grados de formalización legal, penetración y éxito. En muchas situaciones, el cooperativismo tradicional se mezcló con el moderno, aunque el segundo ha prevalecido en la mayoría de los casos. Muchos sectores han planteado la necesidad de un cambio de modelo frente a la inestabilidad y la crisis que ha vivido el sistema financiero - ante el cual el cliente ha demostrado su desconfianza-, que deberá rescatar valores y principios que ha perdido nuestra sociedad moderna. El sector de la economía popular y solidaria - en especial, el sistema cooperativo de ahorro y crédito- es una alternativa que merece atención por parte del Estado.

En el sistema cooperativo de ahorro y crédito se practican de mejor manera los principios de solidaridad, ayuda mutua, autogestión 


\section{0 / VOL. 17 / NO. 44 / JULIO-DICIEMBRE 2016}

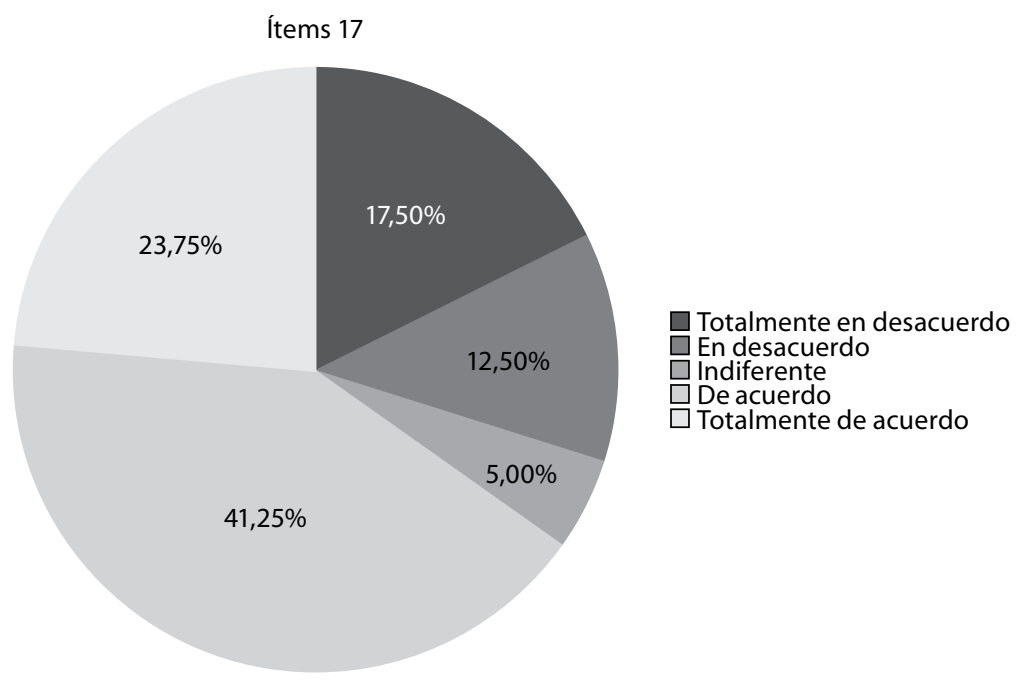

\section{Gráfica 7}

La implementación de un sistema de costos basado en actividades es de gran relevancia para la cooperativa en razón a que genera información aproximada a la realidad, dotando de un alto grado de confianza la toma de decisiones Fuente: resultados de la encuesta aplicada (2013)

y control democrático. Poniendo el desarrollo del hombre como objetivo fundamental de su actividad que, por supuesto debe modernizarse y ser manejada con conocimientos técnicos, para brindar los servicios de una manera eficiente, efectiva y económica. La gestión de costos es un instrumento eficaz para la dirección, ya que permite medir el comportamiento de la actividad económica de las empresas y, como arma de dirección, facilita la valoración de posibles decisiones y elegir aquellas que proporcionan los mejores resultados productivos con un mínimo de gastos; y reducir el riesgo de tomar decisiones incorrectas (Superintendencia de Bancos y Seguros de Ecuador, 2010).

Por la carencia de investigaciones en la temática específica se puede observar que en todos los países de América Latina entienden que la gestión de los costos es imperiosa para la toma de decisiones, pero ninguna reconoce la metodología $\mathrm{ABC}$ como la más propicia para lograrlo y utilizan una herramienta de gestión de costos acompañada con una estrategia de costo y, a partir de la información obtenida, toman las decisiones.

Países como Argentina, Chile, México o Brasil presentan una legislación clara sobre el funcionamiento y administración de las cooperativas. En el Sistema Económico y Rentístico de la Confederación Argentina según su Constitución de 1853, Juan Bautista Alberdi vuelve a hacer hincapié en la importancia que tienen los empresarios y sus empresas a la hora de promover el crecimiento del país, el progreso de sus habitantes y la sostenibilidad de sus corporaciones de ahorro y crédito (Alberdi, 1854, p. 240). El enfoque evolucionista, más allá de sus limitaciones (Coriat \& Weinstein, 1995), ayuda, por un lado, a des- 
homogeneizara la firma, haciendo hincapié en la diversidad del comportamiento empresario y, por otro, a poner en primer plano el papel de la empresa en los procesos de innovación en un contexto de racionalidad limitada e incertidumbre. A su vez, contribuye a una comprensión más abarcadora de las complejas relaciones entre mercados, marco institucional y desempeño empresario, para enfatizar la necesidad de analizar en cada caso concreto el funcionamiento de los mecanismos selectivos y el tipo de conducta empresaria que ellos premian y/o castigan.

Todo esto permite identificar que en América Latina el objeto de este artículo no ha sido estudiado y da posibilidades a una ampliación de investigaciones y comparaciones entre países hermanos.

\section{Conclusiones}

Con la información adquirida al aplicar el instrumento de información primaria a las instituciones solidarias del cooperativismo que ejercen actividades de ahorro y crédito en la ciudad de Barranquilla como referencia, se puede concluir lo explicitado en los siguientes párrafos.

En primera instancia, a partir del proceso investigativo realizado, es posible concluir que las instituciones solidarias que ejercen actividades de ahorro y crédito como gran parte de su objeto social en la ciudad de Barranquilla, en su gran mayoría, utilizan herramientas administrativas con las cuales proceden a asignar las erogaciones necesarias y obligatorias al servicio prestado.

En este sentido, el proceso analítico efectuado en las cooperativas objeto de estudio, permite establecer que esos procedimientos institucionales se caracterizan por utilizar bases históricas y predeterminadas al momento de fijar el costo de los servicios ofrecidos a la sociedad en general.

No obstante, de la información adquirida, se puede deducir que los diferentes sistemas de gestión de costos utilizados por las instituciones estudiadas presentan grandes inconvenientes al momento de generar información útil y pertinente para la toma de decisiones, por las dificultades para calcular la utilidad de las operaciones realizadas, los problemas en el suministro de información financiera y no financiera para analizar el comportamiento de los costos indirectos de fabricación y los inconvenientes para realizar comparaciones homogéneas y coherentes. Por otro lado, los sistemas de costos utilizados por las organizaciones solidarias estudiadas no permiten conocer los procesos y actividades que estructuran la organización para determinar cuál de ellos está generando valor a la institución perteneciente a la economía solidaria.

Finalmente, los agentes encargados de la identificación, valoración, medición y revelación de información financiera, administrativa y social en las entidades objeto de estudio, son consecuentes al expresar que - como consecuencia de estas debilidades de los sistemas acumulativos de costos utilizados por ellasconsideran de especial relevancia la implementación del sistema de costos ABC, en razón a que en el entorno organizacional actual este se ha constituido en una herramienta corporativa que propende por la adecuada asociación de los costos obligatorios y necesarios en 
la prestación de servicios, concibiendo información que trasciende más allá de las bases monetarias y financieras, en miras al establecimiento de las causas y el comportamiento de los CIF, para fundamentar el proceso de toma de decisiones por parte de los agentes encargados de hacerlo.

Tomando como referencia las conclusiones de los párrafos anteriores, es posible recomendar a las instituciones solidarias del cooperativismo que ejercen actividades de ahorro y crédito en la ciudad de Barranquilla que, a raíz de que la información generada por los sistemas de costos que utilizan no se caracteriza por producir insumos sólidos para cimentar el proceso de toma de decisiones, se considera vital que desarrollen sus actividades bajo la metodología de costos $\mathrm{ABC}$ para que puedan identificar de manera clara cuáles son las áreas generadoras de valor (ingresos) y cuáles son unidades de apoyo o creadoras de inversiones (costos y gastos), ya que con esta información van a poder diseñar una estructura de costos acorde a sus necesidades, para que estos sean distribuidos y asignados a sus productos y servicios de acuerdo a las unidades creadoras de valor.

\section{Referencias}

Alberdi, Juan Bautista (1854). Sistema Económico y Rentístico de la Confederación Argentina según su Constitución de 1853. Disponible en: https://archive.org/stream/ sistemaeconmic00albeuoft\#page/n7/ mode/2up, http://www.hacer.org/pdf/ sistema.pdf
Altahona-Quijano, Teresa de Jesús (2009). Libro práctico de contabilidad de costo. Bucaramanga: Universidad de Investigación y Desarrollo, UDI. Disponible en: http:// datateca.unad.edu.co/contenidos/106002/ UNIDAD_3/contabilidad_general.pdf Alvarado-Mazariegos, Zulma Yadira (julio de 2011). Diseño de un sistema de costos estándar para una empresa productora de jugo de noni. Tesis de grado, Guatemala, Guatemala, Universidad de San Carlos, Facultad de Ciencias Económicas.

Disponible en: http://biblioteca.usac.edu. gt/tesis/03/03_3822.pdf

Asociación Española de Contabilidad y Administración de Empresa, AECA, Comisión de Principios de Contabilidad de Gestión (2003). El marco de la contabilidad de gestión. Madrid: AECA, Documento No. 1.

Bernal-Torres, César Augusto (2006). Metodología de la investigación. Administración, economía, humanidades y ciencias sociales. México: Pearson.

Caldera, Jorge; Baujín-Pérez, Pilar; Ripoll-Feliu, Vicente \& Vega-Falcón, Vladimir (2007). Evolución de la configuración de los sistemas de costos basados en las actividades. Actualidad Contable FACES, 10 (14), 13-28. Disponible en: http://www.redalyc.org/ pdf/257/25701403.pdf

Carrión-Nin, José Luis (2002). Costos estándar-ABC para la industria de plásticos - Líneas de tuberías y accesorios PVC. Caso: Surplast S.A.C. Tesis de grado de maestría, Lima, Perú, Universidad Nacional Mayor de San Marcos, Facultad de Ciencias Contables. Disponible en: http://sisbib. 
unmsm.edu.pe/bibvirtualdata/tesis/empre/ carri\%C3\%B3n_n_j/tcompleto.pdf

Cerdá-Gutiérrez, Hugo (1995). Los elementos de la investigación. Cómo reconocerlos, diseñarlos y construirlos. Bogotá: El Búho.

Coriat, Benjamin \& Weinstein, Olivier (1995). Les nouvelles théories de l'entreprise. Paris: LGF, Le livre de poche.

Cuervo-Tafur, Joaquín; Osorio-Agudelo, Jair Albeiro \& Duque-Roldán, María Isabel (2007). Costeo Basado en actividades $A B C$ - . Gestión basada en actividades $A B M-$. Valencia: ECOE Ediciones.

Cuevas-Villegas, Carlos Fernando (2001). Contabilidad de costos. Bogotá: Pearson Educación de Colombia Ltda.

Cuevas-Villegas, Carlos Fernando (2002). Fijación de precios: costo plus (costo más margen) y target costing (costeo objetivo). Estudios Gerenciales, 83, 13-30. Disponible en: https://www.icesi.edu.co/revistas/ index.php/estudios_gerenciales/article/ view/80/78

Esteban-Salvador, María Luisa (1998). La contabilidad de gestión como herramienta para la toma de decisiones. Proyecto Social: Revista de Relaciones Laborales, 6, 85-96. Disponible en: https://dialnet.unirioja.es/ descarga/articulo/229732.pdf

Gómez, Marcelo M. (2006). Introducción a la metodología de la investigación científica. Córdoba: Editorial Brujas.

Gómez-Chiñas, Carlos (2002). La economía institucionalista y la contabilidad de gestión. Análisis Económico, XVII (35), 79-92. Disponible en: http://www.redalyc.org/ pdf/413/41303503.pdf
Guevara-Carbajal, Nidia Lisseth; RamírezLemus, Jaime Alejandro \& Vásquez, Bruno Paul Alexander (2010). Diseño e implementación de un sistema de costos para mejorar la toma de decisiones financieras en una empresa dedicada a la elaboración de medicina natural. Trabajo de investigación, San Salvador, El Salvador, Universidad de El Salvador, Facultad de Ciencias Económicas, Escuela de Contaduría Pública. Disponible en: http:// ri.ues.edu.sv/370/1/10136656.pdf

Hargadon, Bernard J. \& Múnera-Cárdenas, Armando (1996). Contabilidad de costos. Bogotá: Norma.

Hernández-Sampieri, Roberto; FernándezCollado, Carlos \& Baptista-Lucio, Pilar (2006). Metodología de la investigación. Naucalpan de Juárez: McGraw-Hill. Disponible en: http://www.dgsc.go.cr/dgsc/ documentos/cecades/metodologia-de-lainvestigacion.pdf

Horngren, Charles T.; Datar, Srikant M. \& Foster, George (2007). Contabilidad de costos. Un enfoque gerencial. México: Pearson Educación.

Horngren, Charles T.; Harrison, Walter T. \& Smith-Bamber, Linda (2003). Contabilidad. $5^{\mathrm{a}}$ ed. México: Pearson Educación. Jaimes-Cruz, Armando (octubre de 2006). Diseño de un sistema de control presupuestal y de gestión estratégica de costos para las empresas manufactureras medianas localizadas en el Distrito Federal y zona conurbana. Tesis de grado, Instituto Politécnico Profesional, México. Disponible en: http://tesis.ipn.mx/ bitstream/handle/123456789/355/TESIS3. 
pdf?sequence $=1$, http://itzamna.bnct.ipn. mx/dspace/bitstream/123456789/355/1/ TESIS3.pdf

Jiménez-Boulanger, Francisco \& Espinoza-Gutiérrez, Carlos Luis (2007). Costos industriales. Costa Rica: Editorial Tecnológica de Costa Rica.

Johnson, Thomas \& Kaplan, Robert S. (1988). La contabilidad de costes: auge y caída de la contabilidad de gestión. Barcelona: Plaza \& Janés Editores.

Kaplan, Robert S. \& Cooper, Robin (2000). Coste \& efecto. Barcelona: Editorial Gestión.

Mercado, Salvador (1997). Mercadotecnia programada: principios y aplicaciones para orientar la empresa hacia el mercado. Ciudad de México: Editorial Limusa.

Miller, Jeffrey G. \& Vollmann, Thomas E. (1985). The Hidden Factory. Harvard Business Review, 63, 142-150. Disponible en: https://hbr.org/1985/09/the-hidden-factory

Möller-Abramo, Guillermo (2011). El sistema de Costes Basado en Actividades (ABC). Implantación en una bodega. Tesis de maestría. Valladolid: Universidad de Valladolid. Disponible en: https://uvadoc. uva.es/bitstream/10324/849/1/TFM118110802.pdf

Peterson-Véjar, Gastón (2002). Contabilidad de costos por procesos. México: Universidad $\mathrm{Au}$ tónoma de Baja California, UABC.

Polimeni, Ralph S.; Fabozzi, Frank J. \& Adelberg, Arthur H. (1997). Contabilidad de costos concepto y aplicación para la toma de decisiones gerenciales. México: McGraw-Hill.
Porter, Michael (1985). Competitive Advantage. Creating and Sustaining Superior Performance. New York: The Free Press.

Ramírez-Padilla, David Noel (2005). Contabilidad administrativa. México: McGraw-Hill.

Reyes-Pérez, Ernesto (2005). Contabilidad de costos. México: Limusa S.A.

Rojas-Medina, Ricardo Alfredo (2007). Sistemas de costos: un proceso para su implementación. Manizales: Centro de Publicaciones Universidad Nacional de Colombia. Disponible en: http://www.bdigital.unal.edu. co/6824/5/97895882800907.pdf

Sinisterra-Valencia, Gonzalo \& Polanco-Izquierdo, Luis Enrique (2007). Contabilidad administrativa. Bogotá: ECOE Ediciones.

Staubus, George J. (1971). Activity Costing and Input-Output Accounting. Homewood, Illinois: Richard D. Irwin.

Superintendencia de Bancos y Seguros de Ecuador (2010). Gestión de costos en las cooperativas de ahorro y crédito que realizan intermediación financiera. Disponible en: http://www.cemla. org/actividades/2010/2010-09RegulacionySupervision/2010-09RegulacionySupervision-12.pdf Vinza-Romero, Silvana Andrea (2012). Propuesta para la aplicación del método de costeo por actividades $A B C$ de la industria Gráficas Olmedo de la ciudad de Quito. Quito, Tesis previa, Universidad Central del Ecuador, Facultad de Ciencias Económicas, Escuela de Estadística y Finanzas, Carrera de Finanzas. Disponible en: http://www. dspace.uce.edu.ec/bitstream/25000/165/1/ T-UCE-0005-20.pdf 
SISTEMAS DE GESTIÓN DE COSTOS EN LAS COOPERATIVAS DE AHORRO / J. OTÁLORA, J. BORDA, A. ESCOBAR / 375

Zapata-Sánchez, Pedro (2007). Contabilidad de costos: herramienta para la toma de decisiones. Bogotá: McGraw-Hill.

- Fecha de recepción: 3 de septiembre de 2015

- Fecha de aceptación: 20 de mayo de 2016

- Disponible en línea: 14 de diciembre de 2016

\section{Para citar este artículo}

Otálora-Beltrán, Jorge Enrique; Borda-Viloria, Jorge Carlos \& Escobar-Castillo, Adalberto Enrique (2016). Sistemas de gestión de costos en las cooperativas de ahorro y crédito de Barranquilla. Cuadernos de Contabilidad, 17 (44), 349-375. https://dx.doi.org/10.11144/Javeriana. cc17-44.sgcC 
